\title{
Food Knowledge and Practices Related to Anemic Conditions among Pregnant Women in Kuala Terengganu Malaysia
}

\author{
${ }^{1}$ Faatimah Bah, ${ }^{1}$ Sakinah Harith, ${ }^{2}$ Teungku Nih Farisni \\ ${ }^{1}$ Faculty of Health Sciences, Universiti Sultan Zainal Abidin, Gong Badak Campus, 21300 Kuala Nerus, Terengganu, \\ Malaysia. \\ ${ }^{2}$ Faculty of Public Health, Teuku Umar University, Aceh, Indonesia.
}

Coresponding author: Sakinah Harith, e-mail: sakinahharith@unisza.edu.my

Co-author: FB: fbah123@gmail.com, TNF: teungkunihfarisni@utu.ac.id

Submitted: $17 / 02 / 2020$ Revised: $20 / 03 / 2020$

Accepted: $19 / 04 / 2020$

Published online: $21 / 04 / 2020$

doi: https://doi.org/10.35308/j-kesmas.v7i1.1708 How to cite this article: Bah, F., Harith, S., \& Farisni, T.H. (2020). Food knowledge and practices related to anemic conditions among pregnant women in Kuala Terengganu Malaysia. J-Kesmas: Jurnal Fakultas Kesehatan Masyarakat (The Indonesian Journal of Public Health), 7(1), 19-28.

\begin{abstract}
Anaemia is defined as a condition indicated by the deficiency of red blood cells (RBCs) or haemoglobin $(\mathrm{Hb})$, and anaemia is still said to be the most prevalent nutritional deficiency during pregnancy. It is a huge contributor to maternal mortality. During pregnancy anaemia not only affects the mother but also the growing foetus, which makes it more dangerous. It has been estimated that nearly half of pregnant women around the world are estimated to be anaemic. Previous studies done in Malaysia found the overall prevalence of anaemia among pregnant women to be $35 \%$. Knowledge in regard to anaemia and food practice are factors that contribute to anaemia. This study aims to determine the relationship between food practices, knowledge in regard to anaemic conditions among pregnant women in Kuala Terengganu. The study was based on samples gathered from 96 pregnant women from Hiliran Health Clinic in Kuala Terengganu. Data collected was based on selfadministered questionnaire and twenty-four-hour diet recall. The data was analysed using Statistical Package for the Social Sciences (SPSS) version 21.0. The prevalence of anaemia was found to be $40.9 \%$ and no association was found between anaemia and sociodemographic factors among pregnant women in Kuala Terengganu. Anaemic pregnant women achieved a higher average score of knowledge regarding anaemia as compared to non-anaemic pregnant women. In conclusion findings of this study suggests that there is average knowledge of anaemia among the given population. Findings also suggest that the overall population had good food practice. Furthermore, implications of the study findings, limitations, and directions for future research were also discussed.
\end{abstract}

Keywords: anaemia; pregnant women; food knowledge and practices

\section{Introduction}

Pregnancy is a unique stage in life where the entire physiological aspect of a women changes in order to meet the needs of the baby growing in the womb of the mother. Adequate amount of energy is needed to meet the needs of both mother and child and maintaining a well-balanced diet is important. Anaemia, which falls under the category of undernutrition, is a condition that develops when your blood doesn't have enough healthy red blood cells or haemoglobin and is caused by lack of iron (Martin, 2016; Farisni et al., 2019). Since pregnancy causes a tremendous change in the physiological aspect of a women, cut off haemoglobin values in regard to anaemia is different during all phases of pregnancy.

Anaemia in pregnancy is defined as a value less than the fifth percentile having haemoglobin level of $11 \mathrm{~g} / \mathrm{dL}$ or less in the first trimester, 10.5 $\mathrm{g} / \mathrm{dL}$ or less in the second trimester, and $11 \mathrm{~g} / \mathrm{dL}$ or less in the third trimester (Rigby, 2016). Iron is a very important essential mineral needed for the production of healthy red blood cells and the lack of it could cause Iron Deficiency Anaemia (IDA). In a normal stage of life, this could easily be treated by taking supplements to meet iron needs, but in pregnancy this becomes a little more complicated. Lack of iron can lead into anaemia which could lead 
to low birth weight of the infant, birth defects as well as mortality (Allen, 2000).

It has been argued that nutritional knowledge is strongly associated with healthy eating and healthy food choices irrespective of demographic variables (Alaunyte et al., 2015). In regard to the relationship between nutritional knowledge and application, nutrition is a foundation for health and development. Proper nutrition contributes in making people stronger and more productive. Healthy eating habits lead to a stronger immune system, less chances of illness, and better health outcome and proper and healthy nutrition is a fundamental key to a better quality of life.

Good food practice in regard to nutrition, could significantly reduce maternal anaemia and thus reduce infant or postpartum mortality and other complications. Over $60 \%$ of maternal deaths happens in the postpartum period and this could be easily be avoided with early detection (Hishamshah et al., 2010). Maternal nutritional status is essentially important due to the fact that maternal malnutrition tends to negatively affect both mother and infant. According to Okunaiya et al., (2016) "Maternal healthy nutrient intake during pregnancy may affect the wellbeing of the pregnant woman and developing foetus, birth outcomes and child's disease in adulthood. As such, malnourished mothers face greater risks during pregnancy and childbirth; in addition, their infants are set off on a weaker physical and mental developmental path".

The prevalence of anaemia in pregnancy in Malaysia is $35 \%$ (Haniff et al., 2007). It has been estimated that nearly half the pregnant women in the world are estimated to be anaemic. According to the WHO (2011) the prevalence of anaemia is $38.9 \%$ to $48.7 \%$ for pregnant women in developing countries in Africa and Asia. According to WHO (2011), the lowest haemoglobin level with the highest prevalence of anaemia were African regions due to malaria, sickle cell, and thalassaemia's. It is a problem that affects more than 56 million women worldwide and two thirds of this number is from Asia, with an overall prevalence of anaemia among pregnant women in Malaysia being 35\%. Factors contributing to maternal anaemia in Malaysia ranges from young age, multi-parity and iron deficiency (Soh et al., 2015).

Gap between pregnancies has also been associated with depletion in iron levels. Maternal malnutrition is a condition that can negatively affect the mother and the unborn child long into adulthood. It physiologically affects the child as well as mentally.

Many studies correlate poor nutrition and reduction of the mental capabilities of a child due to irreversible damage to the infant brain (Eni-olorunda, 2015). There are many factors that contribute to poor nutrition in pregnancy. These factors range from socioeconomic, nutrition knowledge and demography (Factors et al., 2013). The main objectives of this study was to determine the relationship between food knowledge and practices related to anaemic conditions among pregnant women in Kuala Terengganu.

\section{Materials and Methods}

\section{Participants and study design}

A cross-sectional study was carried out, which involved 96 pregnant women aged from 21 to 40 years.Subjects were recruited via outpatient waiting room in the maternal unit of Hiliran Health Clinic. All participant was screened for inclusion. Participants were eligible for study inclusion if they aged from 21 to 40 years, able to communicate in Malay, literate, pregnant women of any trimester, no chronic diseases and provide informed consent.

Approval was received from UniSZA Human Research Ethic Committee (UHREC) on the $5^{\text {th }}$ of January 2017, Reference Number: UniSZA.C/1/UHREC/628-1 jld.2 (09). Approval was received by the Medical Research and Ethics Committee (Jawatankuasa Etika \& Penyelidikan Perubatan) on the $7^{\text {th }}$ March 2017, Reference Number: (5) KKM/NIHSEC/P17-323 in order to conduct my study. Finally, another approval letter from Pejabat Kesihatan Daerah Kuala Terengganu (PKD) on the $22^{\text {nd }}$ of January 2017, Reference Number: PKD.KT.100/01/4 Jld.2 (39).

Participants in this study was kept anonymous and confidentiality was taken in high regards. Subjects were given a consent form to sign before the 
research was conducted in order to ensure the privacy of the participant is kept.

\section{Data collection}

The method for collecting data for this study is self-administered questionnaires. The respondents are pregnant women of any trimester at Hiliran Health Clinic in Kuala Terengganu. The respondents completed the survey questionnaire on their own. The questionnaire for this study consists of 4 sections including the demographic section. Section 1 includes the demographic information about the patient. Section 2 measures the knowledge of the pregnant woman in regard to iron deficiency anaemia.

The number of questions consist of 6 items, they are an assessment of knowledge in regard to anaemia, symptoms of anaemia, causes of anaemia and the importance of iron supplements, iron rich food sources and child spacing. Respondents are asked to indicate yes, no or I don't know. Section 3 measures food practice in regards to iron deficiency anaemia adapted from the work of Abu-hasira (2007) and the number of questions consists of eight items.

The respondents are asked to indicate yes and no. Section 4 consists of biochemical data indicating the pregnancy term and haemoglobin level taken from the patients records, and figures were obtained from the work of Rigby (2016). Dietary intake is taken via twenty-four -hour diet recall in a form of an interview. This enabled us to estimate the total food intake in regard to important macronutrients, micronutrients and vitamins.

\section{Statistical analysis}

The data collected was analysed using the statistical package Statistical Package for the Social Sciences (SPSS) version 22.0 software. Pearson's Chi square test will be used to estimate the association of dependant and independent variables on haemoglobin level. Linear regression will be used to find the effect of the different variables on the outcome variable. Independent t-test was used to find the mean dietary intake between Anaemic and none anaemic participants.

The questionnaire used included demographic data, knowledge on anaemia and food practice and descriptive statistics was used to find the frequency. Finally, Nutritionist Pro Version 3.1.0 was used to analyse dietary intake obtained from the 24-hour diet recall from participants.

\section{Results}

A total of 96 pregnant women were recruited. Out of 96 of the subjects, $5(5.2 \%)$ were excluded as inclusive criteria was not met and 3 (3.1\%) did not have their haemoglobin value $(\mathrm{Hb})$ therefore, the final total usable data was 88 .

\section{Socio-demographic profile of respondents}

The demographic variables used in the current study are gender, age, race, level of education, number of kids and household income. Descriptive statistics are statistics that quantitatively describe or summarize features of a collection of information (Mann, 1995). In this section the frequency and percentage for each given data is clearly shown.

Table 1 summarizes all the demographic data into one table. All 88 participants of this study were all pregnant females and $43 \%(n=38)$ of them age ranged between 26 to 30 years old while $25 \%$ (22) of them age ranged between 31 to 35 years old. $23 \%$ $(n=20)$ were below the age of 26 , while only $9 \%$ $(n=8)$ of the participants exceeded the age of 35 years old, therefore most of the participants were of healthy reproductive age range.

In terms of level of education of participants, majority of the participants had secondary school level of education, this composed of $51.1 \%(n=45)$ of the total sample size. Only $2.3 \%(\mathrm{n}=2)$ of them had below secondary school level of education but were literate enough to understand questions given in the questionnaire. 28.4\% $(\mathrm{n}=25)$ held a diploma, while $18.2 \%(\mathrm{n}=16)$ of them qualified in higher education.

A total of $97.8 \%(n=86)$ of the given population were married, and $98.9 \%(n=87)$ of them were Malay (ethnic group). $54.5 \%(\mathrm{n}=48)$ of them had $0-1$ child while $39.8 \%(n=35)$ had $2-5$ children, most of them being pregnant with their first child. Only $5.7 \%(n=5)$ of them had more than 5 children. Finally, in respect to the overall household income, $47.6 \%(n=41)$ claimed to have an overall household income of less than or equal to RM 1000, while $38.1 \%(\mathrm{n}=32)$ income ranged between RM 2000-RM 
Table 1: Sociodemographic data $(n=88)$

\begin{tabular}{|c|c|c|c|}
\hline Socio-demographic variable & Items & Frequency (n) & Percentage $(\%)$ \\
\hline Gender & Female & 88 & 100 \\
\hline Age & $\begin{array}{l}21-25 \\
26-30 \\
31-35 \\
36-40 \\
\end{array}$ & $\begin{array}{c}20 \\
38 \\
22 \\
8\end{array}$ & $\begin{array}{c}23 \\
43 \\
25 \\
9\end{array}$ \\
\hline Level of education & $\begin{array}{c}\text { Low } \\
\text { Secondary school } \\
\text { Diploma } \\
\text { Bachelor degree } \\
\text { Graduate }\end{array}$ & $\begin{array}{c}2 \\
45 \\
25 \\
14 \\
2\end{array}$ & $\begin{array}{c}2.3 \\
51.1 \\
28.4 \\
15.9 \\
2.3\end{array}$ \\
\hline Marital Status & $\begin{array}{l}\text { Single } \\
\text { Married } \\
\text { Other }\end{array}$ & $\begin{array}{c}1 \\
86 \\
1\end{array}$ & $\begin{array}{c}1.1 \\
97.8 \\
1.1\end{array}$ \\
\hline Race & $\begin{array}{c}\text { Malay } \\
\text { Chinese }\end{array}$ & $\begin{array}{c}87 \\
1\end{array}$ & $\begin{array}{c}98.9 \\
1.1\end{array}$ \\
\hline Number of kids & $\begin{array}{c}0-1 \\
2-5 \\
\text { More than } 5\end{array}$ & $\begin{array}{c}48 \\
35 \\
5\end{array}$ & $\begin{array}{c}54.5 \\
39.8 \\
5.7\end{array}$ \\
\hline Household income & $\begin{array}{l}\leq \text { RM } 1000 \\
\text { RM 2000-3000 } \\
\geq \text { RM } 4000\end{array}$ & $\begin{array}{l}40 \\
32 \\
12\end{array}$ & $\begin{array}{l}47.6 \\
38.1 \\
14.3\end{array}$ \\
\hline Stage of trimester data & 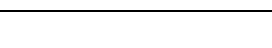 & & \\
\hline $1^{\text {st }}$ Trimester & $\begin{array}{l}21-25 \mathrm{yr} \\
26-30 \mathrm{yr} \\
31-35 \mathrm{yr} \\
36-40 \mathrm{yr}\end{array}$ & $\begin{array}{l}4 \\
8 \\
2 \\
2\end{array}$ & 18.2 \\
\hline $2^{\text {nd }}$ Trimester & $\begin{array}{l}21-25 \mathrm{yr} \\
26-30 \mathrm{yr} \\
31-35 \mathrm{yr} \\
36-40 \mathrm{yr}\end{array}$ & $\begin{array}{l}7 \\
9 \\
4 \\
1\end{array}$ & 23.9 \\
\hline $3^{\text {rd }}$ Trimester & $\begin{array}{l}21-25 \mathrm{yr} \\
26-30 \mathrm{yr} \\
31-35 \mathrm{yr} \\
36-40 \mathrm{yr}\end{array}$ & $\begin{array}{c}9 \\
23 \\
15 \\
4\end{array}$ & 57.9 \\
\hline
\end{tabular}

\section{Prevalence of Anaemia}

The prevalence of anaemia among pregnant women in Kuala Terengganu was found to be $40.9 \%$ $(n=88)$. Table 2 clearly shows that the prevalence of anaemia was highest amongst women in their third trimester $26.1 \%(n=23)$ compared to women in their second trimester $10.3 \%(\mathrm{n}=9)$ and women in their first trimester $4.5 \%(\mathrm{n}=4)$.
Table 2: Prevalence of anaemia $(\mathrm{n}=88)$

\begin{tabular}{ccc}
\hline Pregnancy Term & Frequency (n) & Prevalence (\%) \\
\hline $1^{\text {st }}$ Trimester & 4 & 4.5 \\
$2^{\text {nd }}$ Trimester & 9 & 10.3 \\
$3^{\text {rd }}$ Trimester & 23 & 26.1 \\
\hline Total & 36 & 40.9 \\
\hline
\end{tabular}


Table 3 classifies the prevalence of anaemia into three categories: mild anaemia, moderate anaemia and severe anaemia. $39.8 \%(\mathrm{n}=35)$ of the participants fell under mild anaemia category, and $1.1 \%(\mathrm{n}=1)$ of the participants was found to be moderately anaemic. There were no severe anaemic cases.

Table 3: Classification of anaemia

\begin{tabular}{lccc}
\hline \multicolumn{1}{c}{ Classification } & Haemoglobin $(\mathbf{H b})$ range (g/dL) & Frequency (n) & Percentage (\%) \\
\hline Mild anaemia & $9-<11$ & 35 & 39.8 \\
Moderate anaemia & $7-<9$ & 1 & 1.1 \\
Severe anaemia & $<7$ & 0 & 0 \\
\hline
\end{tabular}

\section{Knowledge of Anaemia}

This section consists of 6 questions that, and each question is divided into categories. Question number 1 has 3 parts (Q1.1, Q1.2 \& Q1.3), question number 2 has 3 parts (Q2.1, Q2.2 \& Q2.3), question number 3 has 5 parts (Q3.1, Q3.2, Q3.3, Q3.4 \& Q3.5), question number 4 has 3 parts (Q4.1, Q4.2, Q4.3, Q4.4, \& Q4.5), question number 5 has 8 parts (Q5.1, Q5.2, Q5.3, Q5.4, Q5.5, Q5.6, Q5.7 \& Q5.8), and question 6 is a multiple choice question with choices a,b,c and d.

In total, questions measuring knowledge on anaemia consisted of 23 questions. Knowledge was assessed by calculating average score of the given question. Knowledge score divided into 3 categories of poor, average and good. Scoring less than or equal to $50 \%$ is considered poor knowledge. Knowledge score between $51 \%$ and $79 \%$ is categorized as having average knowledge, while scoring above $80 \%$ is good knowledge (Table 4).

Table 4: Knowledge of anaemia

\begin{tabular}{lcc}
\hline \multicolumn{1}{c}{ Knowledge } & Anaemic (\%) & Non-anaemic (\%) \\
\hline Q1. What is anaemia? & 48 & 45 \\
Q2. Symptoms of anaemia & 51 & 54 \\
Q3. Causes of anaemia & 31 & 36 \\
Q4. Importance of iron supplements & 92 & 90 \\
Q5. Iron rich food sources & 61 & 60 \\
Q6. Best spacing period & 43 & 57 \\
\hline
\end{tabular}

\section{Food Practices}

Food practice of non-anaemic patients were analysed descriptively. Question 7 is divided into nine items and each item has two choices "YES" or "NO". Question 7.1 is "drinking tea with meal". $85 \%$ claimed not to drink tea with meal, while only $15 \%$ claimed to drink tea with a meal. Question 7.2 is "use of iron supplements with fruit juice". $91 \%$ claimed to use iron supplement with fruit juice, whilst only a small amount of $9 \%$ claimed not to take iron supplements with fruit juice. Question 7.3 is "regular use of iron supplement".

Compliance of iron supplements was very low with $84 \%$ claiming not to use iron supplements regularly. Only $16 \%$ claimed to use iron supplements regularly.

Question 7.4 is "use of iron supplement after eating". A total of $56 \%$ claimed they do not take iron supplements after eating and only $44 \%$ claim to take iron supplements after eating. Question 7.5 is "use of three regular meals". $80 \%$ of patients seem to take 3 regular meals per day, while $20 \%$ beg to differ. Question 7.6 is "use of anti-acid". 62\% claim not to use anti-acid, while only $38 \%$ claim to use anti-acid. Question 7.7 is "use of iron supplement with milk or any other type of milk products". $75 \%$ claim to consume iron supplements with milk and milk products, while $25 \%$ do not take iron supplements with milk and milk products. Question 7.8 is "eating 
red meat, liver, chicken and fish". 94\% participants claim to eat red meat, liver, chicken and fish, while only a small fraction of $4 \%$ claim to not eat these foods. Question 7.9 is "eating legumes, fruits and vegetables", again similar results can be seen with $95 \%$ of participants claiming to consume legumes, fruits and vegetables, whilst $5 \%$ claiming not to.

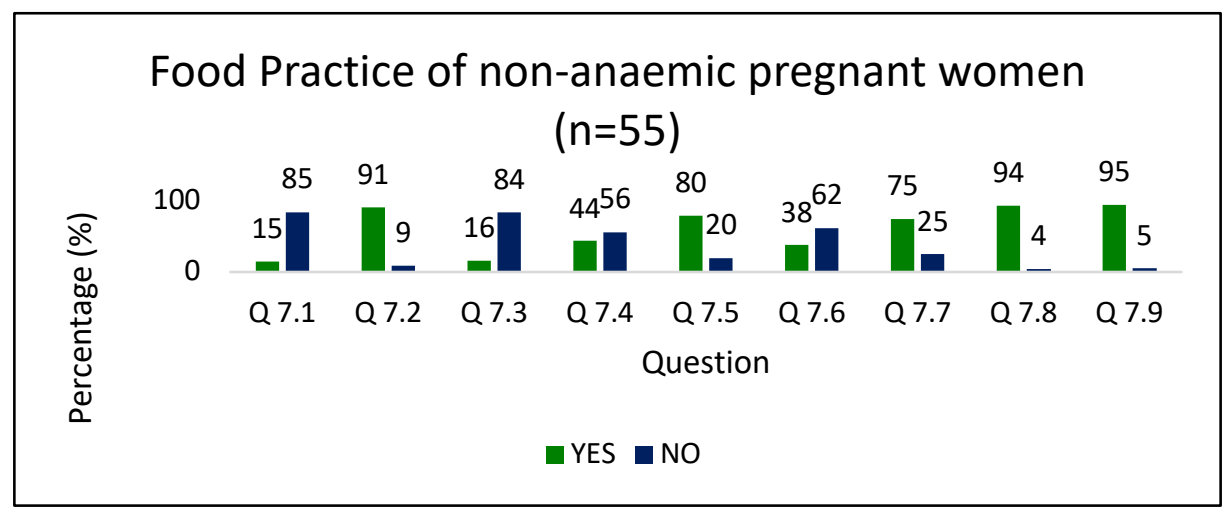

Figure 1: Average food practice score of non- anaemic pregnant women $(n=55)$

Question 7.1 is "drinking tea with meal. 86\% claimed not to drink tea with meal, while only $14 \%$ claimed to drink tea with a meal. Question 7.2 is "use of iron supplements with fruit juice". $97 \%$ claimed to use iron supplement with fruit juice, whilst only a small amount of $3 \%$ claimed not to take iron supplements with fruit juice. Question 7.3 is "regular use of iron supplement". Compliance of iron supplements was very low with $78 \%$ claiming not to use iron supplements regularly. Only $22 \%$ of claimed to use iron supplements regularly.

Question 7.4 is "use of iron supplement after eating". $69 \%$ claimed they do take iron supplements after eating and only $31 \%$ claim they do not take iron supplements after eating. Question 7.5 is "use of three regular meals". $81 \%$ of patients seem to take 3 regular meals per day, while $19 \%$ beg to differ. Question 7.6 is "use of anti-acid". $75 \%$ claim not to use anti-acid, while only $25 \%$ claim to use anti-acid.

Question 7.7 is "use of iron supplement with milk or any other type of milk products". $78 \%$ claim to consume iron supplements with milk and milk products, while $22 \%$ do not take iron supplements with milk and milk products. Question 7.8 is "eating red meat, liver, chicken and fish". 97\% participants claim to eat red meat, liver, chicken and fish, while only a small fraction of $3 \%$ claim to not eat these foods. Question 7.9 is "eating legumes, fruits and vegetables", again similar results can be seen with $94 \%$ of participants claiming to consume legumes, fruits and vegetables while $6 \%$ claiming not to.

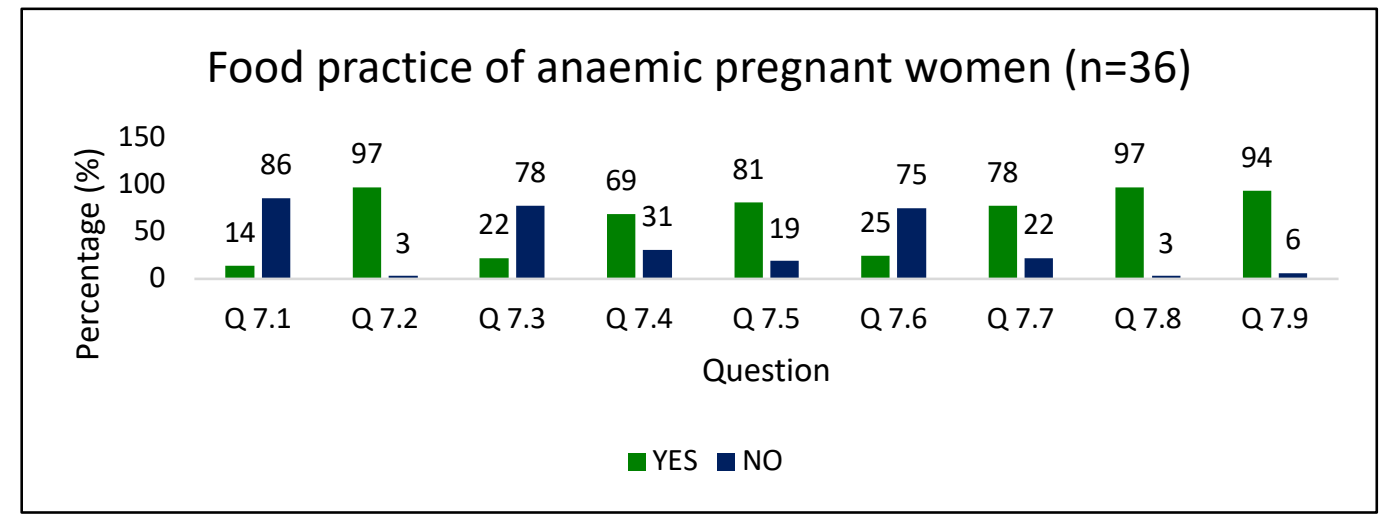

Figure 2: Average food practice score of anaemic pregnant women $(n=36)$ 


\section{Dietary intake}

Among the pregnant women in Kuala Terengganu, twenty-four-hour diet recall was used as a means to obtain dietary intake, and independent ttest was used to analyse this data $(N=88)$. It was found that there was no statistically significant difference between total energy intake between anaemic patients $(1011.32 \pm 439.78)$ and nonanaemic patients $(1086.60 \pm 443.40), t=0.786, \mathrm{p} \geq$ .05 . Therefore, the study failed to reject the null hypothesis that there is no difference in total energy intake between anaemic and non-anaemic patients.
Table 4.6 summarizes the dietary intake between anaemic and non-anaemic patients, and the same could be said about most of the other nutrients such as carbohydrates, proteins, fat and so on. It is clearly seen that anaemic patients tend to consume less nutrients than non-anaemic patients, but the difference between the two groups is very low. It has also been found that there was no statistically significant difference between total iron intake between anaemic patients $(11.55 \pm 13.51)$ and nonanaemic patients $(13.58 \pm 11.48), \mathrm{t}=0.76, \mathrm{p} \geq .05$ (Table 5).

Table 5: Independent t-test between anaemic and non-anaemic pregnant women with mean dietary Intake of the respondents $(\mathrm{n}=88)$

\begin{tabular}{|c|c|c|c|c|}
\hline Variable & $\begin{array}{c}\text { Anaemic } \\
\text { Pregnant women } \\
(\mathrm{n}=36)\end{array}$ & $\begin{array}{c}\text { Non-anaemic } \\
\text { pregnant women } \\
(\mathrm{n}=52)\end{array}$ & $\mathbf{t}$ & P-Value \\
\hline & Mean \pm SD & Mean \pm SD & & \\
\hline Total Energy (kcal) & $1011.32 \pm 439.78$ & $1086.60 \pm 443.40$ & 0.786 & 0.434 \\
\hline Carbohydrates (g) & $145.98 \pm 63.66$ & $159.22 \pm 65.19$ & 0.953 & 0.343 \\
\hline Proteins (g) & $37.51 \pm 18.23$ & $38.27 \pm 16.96$ & 0.200 & 0.842 \\
\hline Fat (g) & $30.73 \pm 18.46$ & $32.80 \pm 17.00$ & 0.541 & 0.590 \\
\hline Vitamin A ( $\mu \mathrm{g})$ & $1436 \pm 3491$ & $783.01 \pm 807.19$ & -1.302 & 0.196 \\
\hline Vitamin B6 (mg) & $0.49 \pm 0.37$ & $0.47 \pm 0.34$ & -0.259 & 0.796 \\
\hline Vitamin B12 $(\mu \mathrm{g})$ & $1.49 \pm 5.05$ & $0.70 \pm 1.01$ & -1.110 & 0.270 \\
\hline Folate $(\mu \mathrm{g})$ & $106.44 \pm 183.27$ & $83.24 \pm 77.17$ & -0.816 & 0.417 \\
\hline Calcium (mg) & $299.75 \pm 177.95$ & $285.97 \pm 194.41$ & -0.338 & 0.736 \\
\hline Iron (mg) & $11.55 \pm 13.51$ & $13.58 \pm 11.48$ & 0.760 & 0.449 \\
\hline
\end{tabular}

\section{Association between anaemia and socio demographic factors}

This study found the association between socio-demographic factors and anaemia, using chisquare test. Chi-Square Test is the most widely used non-parametric statistical test that describes the magnitude of discrepancy between the observed data and the data expected to be obtained with a specific hypothesis (Jargons, 2016). Sociodemographic data was divided into categories that are thought to influence anaemia. Results indicate that there is no association $(\mathrm{p}>0.05)$ between age, household income, number of kids and number level of education with haemoglobin level.

\section{Discussion}

The prevalence of anaemia was found to be $40.9 \%(n=88)$ and to be more of the mild type, therefore, the hypothesis states that: Anaemia is prevalent among the pregnant women population of Kuala Terengganu. There were other similar studies conducted within Malaysia, and prevalence of anaemia ranged from $30-42 \%$ and fall into the categories of moderate to severe anaemia. A previous study done by Haniff et al., (2007), found the prevalence of anaemia to be $35 \%$ and more of the mild type. This study also found prevalence of anaemia to be more prevalent among Indians and Malays. Another recent study by Soh et al., (2015), found the prevalence of anaemia to be $33 \%$ which is much lower. According to a WHO survey (McLean et al., 2009) the prevalence of anaemia among pregnant women is $38 \%$. In comparison to neighbouring countries such as Singapore, the prevalence of anaemia is very low of $29 \%$. 
This study found the prevalence of anaemia to be highest during $3^{\text {rd }}$ trimester $(26.1 \%)$ as compared to second $(10.3 \%)$ and first trimester $(4.5 \%)$. This occurrence could be explained to the fact that the demands for iron increases as the mother reaches full term. As the mother reaches her $3^{\text {rd }}$ trimester, blood plasma volume increases drastically, due to this more iron is needed to be sufficient (Tabrizi \& Barjasteh, 2015). Chances are that if mother enters $3^{\text {rd }}$ trimester with low iron levels, this increases her risk of developing anaemia during late stages of pregnancy which is proven to be more dangerous.

According to Haniff et al., (2007), post-partum haemorrhage is said to be the leading cause of maternal mortality. Anaemia could be linked to this problem as ensuring good levels of haemoglobin level before labour could go a long way.

In this study, overall, non-anaemic participants proved to have higher knowledge on anaemia than anaemic participants. Non-anaemic participants scored an overall average of $57 \%$ as compared to anaemic participants that scored an overall average of $54 \%$. The difference isn't that great, but every pointer counts when assessing knowledge. Even though anaemic mothers overall score on knowledge of anaemia was low, this cannot be said for all the categories that were included.

On general knowledge on what is anaemia, anaemic participants scored $48 \%$ whilst non-anaemic participants scored an average of $45 \%$. This could be explained as that anaemic mothers are briefed by health professionals upon diagnosis of their condition and they're also briefed on to how to manage it as per protocol. Most anaemic mothers knew they had anaemia and had some sort of idea as to what their condition was and had a general idea on what is anaemia. In symptoms of anaemia, non-anaemic mothers scored higher with an average score of 54\% as compared to anaemic mothers that scored an average of $51 \%$.

In terms of the causes of anaemia non-anaemic mothers again scored higher with an average score of $36 \%$ as compared to non-anaemic mother that scored an average of $31 \%$. On the importance of iron supplements, anaemic mothers ironically scored higher with an average score of $92 \%$ as compared to non-anaemic mothers that scored an average score of
90\%. Again, in knowledge regarding iron rich food sources, anaemic mothers proved to be very knowledgeable on this area and scored an average of $61 \%$ as compared to non-anaemic mothers that scored an average of $60 \%$.

Finally, in knowledge on the best spacing period between having children, non-anaemic mothers scored higher with an average score of 57\% as compared to anaemic mothers that scored an average score of $43 \%$. It can be clearly seen that most of the scores were close to each other with not much difference between each group.

In another study amongst pregnant women knowledge regarding cause of anaemia, symptoms of anaemia and iron rich food sources were poor (Yadav et al., 2014). This study contradicts this current research as knowledge regarding causes of anaemia was quite poor as it was $<50 \%$ but knowledge regarding symptoms of anaemia and iron rich food sources were quite good as the average score was $>50 \%$.

A total of 9 questions were asked in regards to food practices. Some were considered to be good food practice while others were considered to be bad food practice. The first question which is whether participants drink tea with meal in controversially considered a bad food practice, and $85 \%$ and $86 \%$ of non-anaemic and anaemic participants do not follow this food practice. The second question which was about the use of iron supplement with fruit juice. This is considered a good food practice, as fruits aids in the absorption of iron into the blood stream. $91 \%$ and $97 \%$ of non-anaemic and anaemic participants follow this food practice.

The third question which is about the regular use of iron supplement is considered a practice as this helps prevent anaemia. One study found that one of the factors that affect prevalence of anaemia has to do with poor compliance of iron supplement (Haniff et al., 2007). Another study claimed that supplement has been linked with the reduction of the severity of iron depletion and especially when it comes to women in their $3^{\text {rd }}$ trimester, nevertheless women who initially had low iron levels, iron supplements does not prove to be efficient in preventing iron deficiency (Allen, 2000). 
Even though regular use of iron supplement is a considered a good practice and is especially important for pregnant women $84 \%$ of non-anaemic mothers tend to have poor compliance of iron supplement, whilst $78 \%$ of anaemic mothers fell into the same category of having poor compliance of iron supplements. This becomes especially dangerous to the pregnant woman especially as she reaches full term.

The fourth question was about the use of iron supplement after eating. It has been said that iron is best absorbed on an empty stomach but due to the properties of iron supplements, it has been associated with nausea, vomiting and so on, therefore iron supplements are encouraged to be taken after eating something and especially when it comes to pregnant mothers due to their gastrointestinal sensitivity. Therefore, the use of iron supplements is considered a good practice. $56 \%$ and $75 \%$ of non-anaemic and anaemic respondents do not take iron supplements after eating. Anaemic respondents scored higher than non-anaemic mothers in bad food practice.

The fifth question was about the use of 3 regular meals. This is considered a good food practice as it is very healthy to eat 3 times a day in order to obtain sufficient nutrients for a healthy life. With a three-regular meal per day, sufficient energy will be provided which increases quality of life. The sixth question is about the use of antacid. Antacids are a class of drug that specifically targets the stomach in order to neutralize it to $\mathrm{pH} 7$. Antacids has been associated with a nutritional deficiency such as vitamin B12. Therefore, the use of antacids is considered a bad practice. $62 \%$ and $75 \%$ of nonanaemic participants and anaemic participants do not take antacids.

The seventh question is the use of iron supplements with milk or any kind of milk products. This is considered a bad food practice as it should not be taken with any product. $75 \%$ and $78 \%$ of nonanaemic and anaemic participants take iron supplements with milk or any kind of milk products.

Finally question eight and question nine both have to do with food consumption. Question 8 is whether participants eat red meat, liver chicken and fish and $94 \%$ and $97 \%$ of non-anaemic and anaemic participants follow this food practice. Question 9 was on whether participants eat legumes, fruits and vegetables. Again, majority of the participants scored very high with an average of $95 \%$ for non-anaemic and $94 \%$ for anaemic. The cultural influence might have been a contributing factor in the variety of foods consumed by the participants. Overall the ratio between good food practices to bad food practice of the overall population is $2: 1$. Therefore we conclude that pregnant women in Kuala Terengganu have good food practice.

According to the results there was no significant associated between anaemia and the influence of socio demographic factors such as age, household income, number of kids and level of education. There was another similar study done that found no association between age and haemoglobin levels among pregnant mothers but found an association between haemoglobin levels and family income (Soh et al., 2015). Contrary to the study, Soh et al., (2015) also found an association between level of education and anaemia. This was explained that the higher education the person has the more health conscious they are. This study proved that with increased level of education there is decrease in the prevalence of anaemia.

According to the WHO (2011), the prevalence of anaemia is $38.9 \%$ to $48.7 \%$ for pregnant women in developing countries in Africa and Asia. This study aimed to determine the relationship between food practices, knowledge and anaemia among pregnant women in Kuala Terengganu. This study found the prevalence of anaemia to be $40.9 \%(n=88)$ of the mild type, with highest in the $3^{\text {rd }}$ trimester. In this study overall nonanaemic participants proved to have higher knowledge on anaemia than anaemic participants. Non-anaemic participants scored an overall average of $57 \%$ as compared to anaemic participants that scored an overall average of 54\%. Overall food practice was found to be good and no association was found to between anaemia and sociodemographic factors.

\section{Conclusion}

In conclusion, good nutrition is very important in every stage of life, but every stage of life requires a different composition and quantity of 
macronutrients, micronutrients and vitamins. Other stages of life emphasize on good nutrition to a great extent in order to reduce undesirable outcomes. Pregnancy is a unique stage in life where the entire physiological aspect of women changes to meet the needs of the baby growing in the womb of the mother. The mother now does not only have to not only care for herself but for the welfare of the growing baby as well. There are many nutritional deficiencies but anaemia is the leading nutritional deficiency worldwide. It has been estimated that nearly half the pregnant women in the world anaemic.

\section{Acknowledgement}

The authors would like to express their gratitude and appreciation to all participating patients and health care providers for their cooperation, support and contribution to this study. Also, special thanks to Miss Ong Ying Qian who helped in the manuscript editing and review.

\section{Author Contribution and Competing Interest}

FB conceived of the presented idea, developed the theory and performed the computations. $\mathrm{SH}$ verified the analytical methods. SH and TNF supervised the findings of this work. All authors discussed the results and contributed to the final manuscript.

\section{Publisher's Note}

J-Kesmas: Jurnal Fakultas Kesehatan Masyarakat (Indonesia Journal of Public Health) remains neutral with regard to jurisdictional claims in published institutional affiliation.

\section{References}

Alaunyte, I., Perry, J. L., \& Aubrey, T. (2015) Nutritional knowledge and eating habits of professional rugby league players: does knowledge translate into practice? J. Internat. Society of Sports Nutrition, 12(1): 18 .

Allen, L. H. (2000) Anemia and iron deficiency: effects on pregnancy outcome. The American Journal of Clinical Nutrition, 71(5): 1280S-1284S.

Daba, G., Beyene, F., Fekadu, H., \& Garoma, W. (2013) Assessment of knowledge of pregnant mothers on maternal nutrition and associated factors in Guto Gida Woreda, East Wollega Zone, Ethiopia.
Journal of Nutrition and Food Science, 3(6): 1-7.

Eni-olorunda, T. (2015) Knowledge and attitude of mothers on risk factors influencing pregnancy outcomes in Abeokuta South Local Government Area, Ogun State, 11(11): 313-324.

Farisni, T.N., Fitriani, F. \& Yarmaliza, Y. (2019) The effectiveness of homemade soymilk in increasing haemoglobin level in pregnant women. J-Kesmas: Jurnal Fakultas Kesehatan Masyarakat (Indones. J. Pub. Health), 6(2): 41-48.

Haniff, J., Das, A., Onn, L. T., Chen, W. S., Nordin, N. M., Rampal, S., Zaher, Z. M. M. (2007) Anemia in pregnancy in Malaysia: A cross-sectional survey. Asia Pacific Journal of Clinical Nutrition, 16(3): 527-536.

Hishamshah, M., Ramzan, M., Rashid, A., Mustaffa, W. W., \& Haroon, R. (2010) Belief and practices of traditional post partum care among a rural community in Penang Malaysia. Internat. J. Third World Medic., 9(2): 1-9.

Jargons, B. (2016) Chi Square Test . Retrieved from Business Jargons: http://businessjargons.com/chisquare-test.html

Martin. L, J. (2016) Understanding Anemia - The Basics. WebMD.

Mann, P. S. (1995) Introductory Statistics. In Wiley (Vol. 2).

McLean, E., Cogswell, M., Egli, I., Wojdyla, D., \& de Benoist, B. (2009). Worldwide prevalence of anaemia, who vitamin and mineral nutrition information system, 1993-2005. Pub. Health Nutrition. 12(4): 444-454.

Okunaiya GA, Fadupin GT, O. D. (2016). Knowledge, attitude and practice of maternal and child foodbased dietary guidelines among pregnant women in urban Slum of Lagos State. Clin. Mother Child Health, 13(2): 1-7.

Rigby, F. B. (2016). Anemia and thrombocytopenia in pregnancy. Medscape. Retrieved from http://emedicine.medscape.com/article/261586overview

Soh, K. L., Rahayu, E., Tohit, M., Japar, S., Geok, S. K., Ab Rahman, N., Raman, R. A. (2015) Anemia among antenatal mother in urban Malaysia. $J$. Biomedic. Medicine, 3: 6-11.

Tabrizi, M \& Barjasteh, S. (2015) Maternal hemoglobin levels during pregnancy and their association with birth weight of neonates. Iranian J. Pediatric Hematol. Oncol. 5(4): 211-217.

World Health Organization (WHO) (2011) The global prevalence of anaemia in 2011. Retrieved from https://www.who.int/nutrition/publications/micronu trients/global_prevalence_anaemia_2011/en/

Yadav R., Swamy, M., \& Banjade B. (2014) Knowledge and practice of anemia among pregnant women attending antenatal clinic in Dr. Prabhakar Kore hospital, Karnataka-A Cross sectional study, IOSR. J. Dent.Medic. Sci. 13(4): 74-80. 